\title{
Intakes of magnesium, calcium and risk of fatty liver disease and prediabetes
}

\author{
Wenshuai Li ${ }^{1}$, Xiangzhu Zhu ${ }^{2}$, Yiqing Song ${ }^{3}$, Lei Fan ${ }^{4}$, Lijun Wu', \\ Edmond K Kabagambe ${ }^{2}$, Lifang Hou ${ }^{5}$, Martha J Shrubsole ${ }^{2,6}$, Jie Liu ${ }^{1, *}$ and Qi Dai ${ }^{2,6, *}$ \\ 'Department of Digestive Diseases of Huashan Hospital, Fudan University, Shanghai 200040, People's Republic of \\ China: ${ }^{2}$ Division of Epidemiology, Department of Medicine, Vanderbilt University School of Medicine, 2525 West \\ End Avenue, Suite 800, Nashville, TN 37203-1738, USA: ${ }^{3}$ Department of Epidemiology, Richard M. Fairbanks \\ School of Public Health, Indiana University, Indianapolis, IN, USA: ${ }^{4}$ Department of Oncology, Longhua Hospital, \\ Shanghai University of Traditional Chinese Medicine, Shanghai, People's Republic of China: ${ }^{5}$ Department of \\ Preventive Medicine, Feinberg School of Medicine, Northwestern University, Chicago, IL, USA: ${ }^{\circ}$ Vanderbilt-Ingram \\ Cancer Center, Vanderbilt University Medical Center, Nashville, TN, USA
}

Submitted 3 August 2017: Final revision received 27 January 2018: Accepted 23 February 2018: First published online 2 April 2018

\begin{abstract}
Objective: Obesity and insulin resistance play important roles in the pathogenesis of non-alcoholic fatty liver disease (NAFLD). Mg intake is linked to a reduced risk of metabolic syndrome and insulin resistance; people with NAFLD or alcoholic liver disease are at high risk of $\mathrm{Mg}$ deficiency. The present study aimed to investigate whether $\mathrm{Mg}$ and $\mathrm{Ca}$ intakes were associated with risk of fatty liver disease and prediabetes by alcohol drinking status.

Design: We analysed the association between $\mathrm{Ca}$ or $\mathrm{Mg}$ intake and fatty liver disease, prediabetes or both prediabetes and fatty liver disease in cross-sectional analyses.

Setting: Third National Health and Nutrition Examination Survey (NHANES III) follow-up cohort of US adults.

Subjects: Nationally representative sample of US adults in NHANES ( $n$ 13 489). Results: After adjusting for potential confounders, Mg intake was associated with approximately $30 \%$ reduced odds of fatty liver disease and prediabetes, comparing the highest intake quartile $v$. the lowest. $\mathrm{Mg}$ intake may only be related to reduced odds of fatty liver disease and prediabetes in those whose Ca intake is less than $1200 \mathrm{mg} / \mathrm{d}$. Mg intake may also only be associated with reduced odds of fatty liver disease among alcohol drinkers.

Conclusions: The study suggests that high intake of $\mathrm{Mg}$ may be associated with reduced risks of fatty liver disease and prediabetes. Further large studies, particularly prospective cohort studies, are warranted to confirm the findings.
\end{abstract}

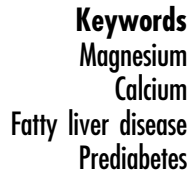

Keywords

Calcium

Prediabetes
All-cause cirrhosis and cancer of the liver are two of the four top leading causes of death from gastrointestinal and liver diseases in the $\mathrm{USA}^{(1)}$. Globally, the mortality rate from cirrhosis and cirrhosis-related diseases has increased over the past 35 years $^{(2)}$. A large portion of liver cirrhosis and cancer is caused by non-alcoholic fatty liver disease (NAFLD) and alcoholic liver disease ${ }^{(3)}$. NAFLD is the most common liver disease in the world ${ }^{(4-6)}$ and includes a spectrum of liver injury ranging from steatosis to severe steatohepatitis that can progress to fibrosis, cirrhosis, liver failure or even liver cancer ${ }^{(7)}$. Unlike alcoholic liver disease which is caused by chronic heavy alcohol use, the aetiology of NAFLD is not clear but may include obesity, type 2 diabetes, use of drugs and exposure to toxic substances ${ }^{(8-10)}$. NAFLD is considered a feature of metabolic syndrome ${ }^{(11)}$.
Mg may be a factor that is related to the aetiology of both alcoholic liver disease and NAFLD. People who chronically drink heavy amounts of alcohol are at high risk of $\mathrm{Mg}$ deficiency ${ }^{(12)}$ and prolonged exposure to alcohol leads to a substantial reduction in $\mathrm{Mg}$ homeostasis in the liver $^{(13)}$. Furthermore, as many as $50 \%$ of type 2 diabetic patients have hypomagnesaemia ${ }^{(14)}$. As such, one previous study found that serum $\mathrm{Mg}$ levels were significantly lower in patients with either alcoholic or non-alcoholic liver steatosis ${ }^{(15)}$. A meta-analysis of randomized trials indicated that $\mathrm{Mg}$ supplementation improves insulin resistance in patients with type 2 diabetes ${ }^{(16)}$. Mg intake has also been linked to a reduced risk of metabolic syndrome $^{(17)}$ and type 2 diabetes ${ }^{(18,19)}$. Very recently, we reported that high intake of $\mathrm{Mg}$ may be associated with a 
reduced risk of mortality due to liver disease, particularly among alcohol drinkers and those with hepatic steatosis ${ }^{(20)}$.

In the present study, we examined whether the intake of $\mathrm{Mg}$ was associated with the prevalence of fatty liver disease or prediabetes. Although previous studies have examined the association between intake of $\mathrm{Ca}$ and type 2 diabetes $^{(21)}$, few studies have examined the role of Ca intake in association with prediabetes ${ }^{(22)}$. Our recent studies indicated that $\mathrm{Ca}$ intake may interact with $\mathrm{Mg}$ intake in relation to diseases of the gastrointestinal tract, such as colorectal adenoma $^{(23)}$, adenoma recurrence ${ }^{(24)}$, reflux oesophagitis, Barrett's oesophagus ${ }^{(25)}$ and other chronic disease $^{(26)}$. Thus, we hypothesized that intake of Ca may also be related to risk of fatty liver disease and prediabetes.

To test these novel hypotheses and to examine whether these associations differ by alcohol drinking status, we analysed data from the Third National Health and Nutrition Examination Survey (NHANES III) follow-up cohort.

\section{Methods}

\section{Study population}

NHANES III was conducted in the USA from 1988 through 1994 by the National Center for Health Statistics of the Centers for Disease Control and Prevention. The institutional review board of the Centers for Disease Control and Prevention approved the investigation, and all participants provided informed consent. It was conducted in two phases, each of which comprised a national probability sample. In total, 39695 participants were selected from a complex, multistage, stratified, clustered probability sample representative of the civilian, non-institutionalized population. Of these participants, 33994 (86\%) were interviewed in their homes. All interviewed participants were invited to the mobile examination centre for a medical examination. In our study, we excluded 15169 participants younger than 20 years old. We also excluded 2210 participants with (i) a physician's diagnosis of diabetes, (ii) glycolated $\mathrm{Hb}$ (HbA1c) $\geq 6.5 \%$ or (iii) fasting glucose $\geq 126 \mathrm{mg} / \mathrm{dl}$. Furthermore, 2178 participants did not complete dietary or supplemental intake assessment and 948 participants had no information on fatty liver disease or prediabetes, thus they were not included in the study. As a result, 13489 participants were included in the final analyses.

\section{Classification of key bealth outcomes}

1. Fatty liver disease cases: An ultrasound examination was performed using a Toshiba Sonolayer SSA-90A and Toshiba video recorder among participants aged 20-74 years in NHANES III between 1988 and 1994. In 20092010, archived gallbladder ultrasound video images were reviewed to assess the presence of fat within the hepatic parenchyma using standard criteria. Followed by five criteria (liver to kidney contrast; brightness of the liver parenchyma; deep beam attenuation; echogenic walls in the small intrahepatic vessels; definition of the gallbladder walls), hepatic steatosis was categorized as normal, mild, moderate or severe. To avoid potential overlap between mild and moderate hepatic steatosis, a categorization of fatty liver disease as 'yes' or 'no' was generally used. 'Yes' indicated moderate or severe hepatic steatosis, while 'no' indicated the liver was normal or had mild hepatic steatosis ${ }^{(27)}$.

2. Prediabetes cases: According to the American Diabetes Association, prediabetes meets the following criteria: (i) no diagnosis of diabetes from a doctor; and (ii) fasting plasma glucose level between 100 and $125 \mathrm{mg} / \mathrm{dl}$ or HbA1c between 5.7 and $6.4 \%{ }^{(28)}$.

3. Both prediabetes and fatty liver disease cases: Those who had both conditions defined above.

4. Controls: Those who had neither fatty liver disease nor prediabetes were regarded as controls.

\section{Nutrient intake assessments}

Detailed dietary and supplemental intakes including $\mathrm{Mg}$ and $\mathrm{Ca}$ were derived from a single $24 \mathrm{~h}$ dietary recall and a $30 \mathrm{~d}$ supplemental interview which participants completed at the mobile examination centre. For the current analyses, only dietary recall data determined by NHANES to be 'reliable (i.e. the individual food files contain records only for participants with complete intake records that were considered to be reliable)' were used. The total intake of these nutrients was calculated by summing up the Mg and $\mathrm{Ca}$ intakes from the dietary and supplemental intakes.

\section{Covariates}

We considered a number of factors as potential confounding factors, including: age (years), sex (men and women), race and ethnicity (non-Hispanic Whites; non-Hispanic Blacks; Other), educational attainment (lower than high-school education; high-school diploma; college graduate or above), ratio of poverty to income $(\leq 1 ; 1-3 ;>3)$, cigarette smoking status (never; former; current), alcohol drinking status (never alcohol drinker: had less than twelve drinks of any kind of alcoholic beverage in entire life; former alcohol drinker: had more than twelve drinks of any kind of alcoholic beverage in entire life but in the past 12 months had less than twelve drinks of any alcoholic beverage; current alcohol drinker: had more than twelve drinks of any kind of alcoholic beverage in entire life and in the past 12 months had at least twelve drinks alcohol), physical activity status (yes: 'have done one or more activities in the past month: jogging/running, swimming, riding a bicycle, aerobics activity, garden/yard work or other activity'; no: 'no activity was done in the past month'), BMI $\left(\mathrm{kg} / \mathrm{m}^{2}\right)$, waist-to-hip ratio, daily intakes of total energy $(\mathrm{kcal} / \mathrm{d}), \mathrm{Ca}(\mathrm{mg} / \mathrm{d})$ and $\mathrm{Mg}(\mathrm{mg} / \mathrm{d})$, use of Ca supplements (yes; no) and use of Mg supplements (yes; no).

\section{Statistical analysis}

All analyses were performed using the Survey package in the SAS statistical software package version 9.4 to account for the applicable weighting in the multistage clustered, probability 
sampling design in the NHANES III cohort. Covariates were compared between cases and controls to evaluate potential confounding factors using the Rao-Scott $\chi^{2}$ test for categorical data and Survey regression models for continuous variables. Survey logistic regression models with fatty liver disease or prediabetes or both prediabetes and fatty liver disease as the dependent variable were used to analyse the association of $\mathrm{Ca}$ or Mg intake with fatty liver disease or prediabetes or both prediabetes and fatty liver disease adjusting for potential confounders. Total $\mathrm{Ca}$ or $\mathrm{Mg}$ intake was included in the models as a categorical variable, using quartiles based on the controls' distribution. To assess the linear trend in the odds of $\mathrm{Ca}$ or $\mathrm{Mg}$ quartile, the median value for each quartile was entered in the logistic regression model as an ordinal variable.
Stratified analyses by sex (men or women), ratio of Ca intake to $\mathrm{Mg}$ intake (Ca:Mg $<2 \cdot 6$ or $\geq 2 \cdot 6$; to be consistent with our previous studies, the cut-off point of 2.6 was used $\left.{ }^{(24)}\right)$, daily Ca intake $(<1200 \mathrm{mg}$ or $\geq 1200 \mathrm{mg})$ and alcohol drinking status (never, former or current alcohol drinker) were conducted. All reported $P$ values were two-sided with statistical significance evaluated at $0 \cdot 05$.

\section{Results}

We compared demographic characteristics and potential confounding factors of cases with fatty liver disease, cases with prediabetes and cases with both prediabetes and fatty liver disease to normal controls (Table 1). Compared with

Table 1 Baseline demographic characteristics and selected risk factors by disease status: US adults aged $\geq 20$ years ( $n$ 13489), Third National Health and Nutrition Examination Survey (NHANES III), 1988-1994*,†

\begin{tabular}{|c|c|c|c|c|c|c|c|c|c|c|c|}
\hline \multirow[b]{2}{*}{ Characteristic } & \multicolumn{2}{|c|}{$\begin{array}{l}\text { Controls } \\
\text { (n 6399) }\end{array}$} & \multicolumn{3}{|c|}{$\begin{array}{c}\text { Fatty liver } \\
\text { disease cases } \\
(n 2423)\end{array}$} & \multicolumn{3}{|c|}{$\begin{array}{l}\text { Prediabetes } \\
\text { cases } \\
(n 5818)\end{array}$} & \multicolumn{3}{|c|}{$\begin{array}{c}\text { Prediabetes } \& \text { fatty liver } \\
\text { disease cases } \\
(n 1511)\end{array}$} \\
\hline & $\begin{array}{c}\text { Mean or } \\
n\end{array}$ & $\begin{array}{l}\text { SD or } \\
\%\end{array}$ & $\begin{array}{c}\text { Mean or } \\
n\end{array}$ & $\begin{array}{c}\text { SD or } \\
\%\end{array}$ & $\begin{array}{c}P \\
\text { value } \neq\end{array}$ & $\begin{array}{c}\text { Mean or } \\
n\end{array}$ & $\begin{array}{l}\text { SD or } \\
\%\end{array}$ & $\begin{array}{c}P \\
\text { value§ }\end{array}$ & $\begin{array}{c}\text { Mean or } \\
n\end{array}$ & $\begin{array}{c}\text { SD or } \\
\%\end{array}$ & $\begin{array}{c}P \\
\text { value } \|\end{array}$ \\
\hline Age at screening (years) & $37 \cdot 8$ & 0.4 & $45 \cdot 6$ & 0.5 & $<0.0001$ & 51.3 & 0.6 & $<0.0001$ & $49 \cdot 3$ & 0.7 & $<0.0001$ \\
\hline Sex $(\%)$ & & & & & $<0.0001$ & & & $<0.0001$ & & & $<0.0001$ \\
\hline Male & 2625 & $43 \cdot 3$ & 1270 & $54 \cdot 7$ & & 3005 & 55.4 & & 646 & $59 \cdot 6$ & \\
\hline Female & 3774 & $56 \cdot 7$ & 1153 & $45 \cdot 3$ & & 2548 & 44.6 & & 505 & $40 \cdot 4$ & \\
\hline Race/ethnicity (\%) & & & & & 0.02 & & & $<0.0001$ & & & $<0.0001$ \\
\hline Non-Hispanic White & 2592 & 78.9 & 877 & $75 \cdot 7$ & & 2201 & 71.9 & & 363 & 69.7 & \\
\hline Non-Hispanic Black & 1737 & $9 \cdot 0$ & 525 & 8.5 & & 1732 & $14 \cdot 1$ & & 297 & 11.5 & \\
\hline Other & 2070 & $12 \cdot 1$ & 1021 & $15 \cdot 8$ & & 1620 & 14.0 & & 491 & $18 \cdot 8$ & \\
\hline Educational attainment (\%) & & & & & $<0.0001$ & & & $<0.0001$ & & & $<0.0001$ \\
\hline Less than high-school graduate & 1841 & $17 \cdot 7$ & 1008 & $27 \cdot 3$ & & 2330 & $30 \cdot 3$ & & 524 & 33.3 & \\
\hline High-school graduate & 2179 & $34 \cdot 3$ & 730 & $35 \cdot 6$ & & 1587 & 33.9 & & 327 & 34.7 & \\
\hline Some college or above & 2248 & $48 \cdot 0$ & 599 & $37 \cdot 1$ & & 1394 & $35 \cdot 8$ & & 245 & $32 \cdot 0$ & \\
\hline Ratio of poverty to income (\%) & & & & & 0.04 & & & 0.001 & & & 0.02 \\
\hline$\leq 1$ & 1283 & $11 \cdot 2$ & 566 & 13.9 & & 1195 & $14 \cdot 0$ & & 279 & $15 \cdot 0$ & \\
\hline $1-3$ & 2707 & $40 \cdot \overline{8}$ & 1035 & 43.2 & & 2324 & 43.0 & & 493 & $45 \cdot 1$ & \\
\hline$>3$ & 1933 & $48 \cdot 0$ & 604 & $42 \cdot 9$ & & 1456 & 43.0 & & 267 & 39.9 & \\
\hline BMl $\left(\mathrm{kg} / \mathrm{m}^{2}\right)$ & $25 \cdot 0$ & $0 \cdot 1$ & $29 \cdot 8$ & 0.3 & $<0.0001$ & 27.5 & 0.1 & $<0.0001$ & $31 \cdot 0$ & 0.3 & $<0.0001$ \\
\hline Smoking status (\%) & & & & & $<0.0001$ & & & $<0.0001$ & & & $<0.0001$ \\
\hline Never smoker & 3373 & $48 \cdot 3$ & 1127 & $42 \cdot 3$ & & 2543 & 41.5 & & 503 & 37.5 & \\
\hline Former smoker & 1171 & $21 \cdot 1$ & 664 & 31.4 & & 1527 & $29 \cdot 3$ & & 354 & $36 \cdot 8$ & \\
\hline Current smoker & 1855 & $30 \cdot 6$ & 632 & $26 \cdot 3$ & & 1482 & $29 \cdot 2$ & & 294 & $25 \cdot 6$ & \\
\hline Alcohol drinking status (\%) & & & & & 0.001 & & & $<0.0001$ & & & 0.0009 \\
\hline Never drinker & 987 & 11.4 & 366 & $12 \cdot 4$ & & 954 & 13.9 & & 169 & 13.7 & \\
\hline Former drinker & 1973 & $27 \cdot 7$ & 813 & 33.3 & & 2074 & $36 \cdot 1$ & & 431 & $36 \cdot 0$ & \\
\hline Current drinker & 3323 & $61 \cdot 0$ & 1190 & $54 \cdot 4$ & & 2358 & $50 \cdot 0$ & & 532 & $50 \cdot 4$ & \\
\hline Physical activity last month (\% yes) & 5302 & 88.4 & 1857 & 83.9 & $<0.0001$ & 4193 & $82 \cdot 4$ & $<0.0001$ & 866 & 81.1 & 0.0002 \\
\hline Daily nutrient intakes & & & & & & & & & & & \\
\hline Total energy $(\mathrm{kJ})$ & 9551 & 106 & 9454 & 154 & 0.56 & 8993 & 109 & 0.0001 & 9333 & 174 & 0.25 \\
\hline Total energy (kcal) & $2282 \cdot 9$ & 25.4 & 2259.5 & $36 \cdot 7$ & 0.56 & $2149 \cdot 3$ & $26 \cdot 0$ & 0.0001 & $2230 \cdot 7$ & 41.6 & 0.25 \\
\hline Total Ca (mg) & 886.9 & $14 \cdot 3$ & 882.5 & $24 \cdot 7$ & 0.84 & 827.5 & $16 \cdot 0$ & 0.001 & $837 \cdot 1$ & 29.7 & 0.09 \\
\hline Ca from diet (mg) & 861.9 & $14 \cdot 2$ & $858 \cdot 1$ & 23.6 & 0.86 & $806 \cdot 4$ & $15 \cdot 5$ & 0.002 & 817.9 & 28.4 & $0 \cdot 12$ \\
\hline Ca from supplements $(\mathrm{mg})$ & $175 \cdot 9$ & $7 \cdot 1$ & 171.0 & 17.6 & 0.79 & $172 \cdot 7$ & 8.3 & 0.76 & $167 \cdot 7$ & 23.0 & 0.73 \\
\hline Total Mg (mg) & $325 \cdot 1$ & 3.8 & 323.7 & $6 \cdot 1$ & 0.83 & 314.4 & $3 \cdot 1$ & 0.01 & 317.4 & 7.5 & 0.34 \\
\hline $\mathrm{Mg}$ from diet (mg) & $309 \cdot 3$ & 3.5 & 308.5 & $5 \cdot 2$ & 0.88 & $300 \cdot 8$ & 2.9 & 0.04 & 305.5 & $6 \cdot 7$ & 0.61 \\
\hline Mg from supplements (mg) & $101 \cdot 4$ & $5 \cdot 3$ & 100.5 & $8 . \overline{7}$ & 0.92 & 99.4 & 3.9 & 0.74 & 93.2 & 11.2 & 0.47 \\
\hline Use of Ca supplements (\% yes) & 905 & $16 \cdot 9$ & 286 & 15.5 & 0.40 & 749 & $15 \cdot 4$ & 0.06 & 143 & $14 \cdot 3$ & $0 \cdot 10$ \\
\hline Use of Mg supplements (\% yes) & 925 & $17 \cdot 3$ & 293 & $15 \cdot 9$ & 0.39 & 765 & $15 \cdot 7$ & 0.04 & 147 & $14 \cdot 6$ & $0 \cdot 10$ \\
\hline
\end{tabular}

*Values are presented as weighted mean and standard deviation for continuous variables; or as unweighted frequency and weighted percentage for categorical variables.

$\dagger P$ values calculated using survey regression model for continuous variables or the Rao-Scott $\chi^{2}$ test for categorical variables; significant $P$ values are indicated in bold font.

$\ddagger P$ value for the comparison between fatty liver disease cases and controls.

$\S P$ value for the comparison between prediabetes cases and controls.

$\| P$ value for the comparison between prediabetes \& fatty liver disease cases and controls. 
controls, cases were older and were more likely to be men, former smokers, former alcohol drinkers, non-Hispanic Black and to have lower educational attainment, higher poverty and higher BMI. Cases with prediabetes consumed lower amounts of $\mathrm{Ca}$ and $\mathrm{Mg}$ compared with controls.

After adjusting for potential confounders, we found that intake of $\mathrm{Ca}$ was not related to the odds of fatty liver disease, prediabetes or both prediabetes and fatty liver disease. On the other hand, we found that intake of $\mathrm{Mg}$ was associated with approximately $30 \%$ reduced odds of fatty liver disease $(P$ for trend $=0.05)$ and prediabetes ( $P$ for trend $=0.02$ ). The association pattern was similar between intake of $\mathrm{Mg}$ and risk of both prediabetes and fatty liver disease although not statistically significant (Table 2).

In stratified analyses, we found that the intake of Ca was marginally associated with increased odds of fatty liver disease among women (Table 3). Also, the intake of Ca may be related to increased odds of prediabetes among those with $\mathrm{Ca}: \mathrm{Mg} \geq 2 \cdot 6$, with an OR of 1.98 (95\% CI 1.07 , 3.67) for the highest quartile intake $v$. the lowest. In the stratified analysis, no significant association was found by drinking status ( $P$ for trend $>0.05$ ). None of the interactions were statistically significant.

The inverse association between the intake of $\mathrm{Mg}$ and risk of prediabetes was significant only among those with Ca:Mg $\geq 2.6$ (Table 4). However, the $P$ for interaction were not statistically significant (Table 4 ). On the other hand, there was a significant interaction between $\mathrm{Mg}$ intake and Ca intake $(P$ for interaction $=0.04)$ in relation to odds of prediabetes. It appears that the intake of $\mathrm{Mg}$ may be related to the reduced odds of fatty liver disease $(P$ for trend $=0.04$ ) and prediabetes ( $P$ for trend $=0.09$ ) only when the intake of $\mathrm{Ca}$ is $<1200 \mathrm{mg} / \mathrm{d}$. In the stratified analysis according to alcohol drinking status, we found that the intake of $\mathrm{Mg}$ may be associated with reduced odds of fatty liver disease only among former drinkers ( $P$ for trend $=0.04$ ) and current drinkers ( $P$ for trend $=0.04)$. However, $P$ for interaction was not statistically significant. We did not find that the association between intake of $\mathrm{Mg}$ and risk of fatty liver and prediabetes differed by sex.

\section{Discussion}

In the NHANES III cohort, a nationally representative sample of the US general population, we found that the intake of $\mathrm{Ca}$ was overall not associated with the odds of fatty liver disease, prediabetes or both. On the other hand, we found that higher intake of $\mathrm{Mg}$ was significantly associated with lower odds of fatty liver disease and prediabetes. Due to limited sample sizes in stratified analyses, we consider the stratified analyses as exploratory. In the stratified analysis, the only significant interaction was between $\mathrm{Mg}$ intake and $\mathrm{Ca}$ intake $(P$ for interaction $=0.04)$ in relation to odds of prediabetes. None of the other interactions were statistically significant. We found that the inverse association between $\mathrm{Mg}$ intake and prediabetes appeared primarily in those with a Ca intake $<1200 \mathrm{mg} / \mathrm{d}$; and in the same subgroup, intake of $\mathrm{Mg}$ was also significantly related to a reduced odds of fatty liver disease. We also found $\mathrm{Mg}$ intake was related to reduced odds of fatty liver disease only among former and current alcohol drinkers.

Our finding of an inverse association between the intake of $\mathrm{Mg}$ and prediabetes is consistent with that of previous studies which have shown that high $\mathrm{Mg}$ intake is associated with a reduced risk of type 2 diabetes ${ }^{(18,29,30)}$, metabolic syndrome $^{(17,31)}$, insulin resistance ${ }^{(32)}$ and prediabetes ${ }^{(33)}$. Furthermore, we found an inverse association between the intake of $\mathrm{Mg}$ and the risk of fatty liver disease. This finding was not consistent with a null association found in a

Table 2 The association of intakes of calcium and magnesium with fatty liver disease, prediabetes and both prediabetes and fatty liver disease, among all subjects: US adults aged $\geq 20$ years ( $n$ 13489), Third National Health and Nutrition Examination Survey (NHANES III), 1988-1994*

\begin{tabular}{|c|c|c|c|c|c|c|c|c|c|}
\hline \multirow[b]{2}{*}{ Daily intake (mg) } & \multicolumn{3}{|c|}{ Fatty liver disease $v$. Controls } & \multicolumn{3}{|c|}{ Prediabetes $v$. Controls } & \multicolumn{3}{|c|}{ Prediabetes \& fatty liver $v$. Controls } \\
\hline & Cases/controls & OR & $95 \% \mathrm{Cl}$ & Cases/controls & OR & $95 \% \mathrm{Cl}$ & Cases/controls & OR & $95 \% \mathrm{Cl}$ \\
\hline \multicolumn{10}{|l|}{$\mathrm{Ca}$} \\
\hline$\leq 431$ & $649 / 1600$ & 1.00 & Ref. & $1919 / 1600$ & 1.00 & Ref. & $335 / 1600$ & 1.00 & Ref. \\
\hline $431-690$ & $621 / 1604$ & 0.97 & $0.76,1.24$ & $1446 / 1604$ & 0.94 & $0.74,1.18$ & $312 / 1604$ & 0.78 & $0.55,1.11$ \\
\hline $690-1063$ & $616 / 1596$ & $1 \cdot 18$ & $0.90,1.54$ & $1285 / 1596$ & 1.04 & $0.82,1.33$ & $274 / 1596$ & 0.81 & $0.64,1.03$ \\
\hline $\begin{array}{l}>1063 \\
P \text { for trend }\end{array}$ & $537 / 1599$ & & $\begin{array}{l}0.85,1.65 \\
16\end{array}$ & \multicolumn{3}{|c|}{0.21} & $230 / 1599$ & 0.89 & $\begin{array}{l}0.54,1.47 \\
76\end{array}$ \\
\hline \multicolumn{10}{|l|}{$\mathrm{Mg}$} \\
\hline$\leq 192$ & $652 / 1615$ & 1.00 & Ref. & $1849 / 1615$ & 1.00 & Ref. & $332 / 1615$ & 1.00 & Ref. \\
\hline$\overline{1} 92-274$ & $572 / 1600$ & 0.83 & $0.59,1.18$ & $1378 / 1600$ & 0.85 & $0.65,1.13$ & $255 / 1600$ & 0.90 & $0.60,1.37$ \\
\hline $274-383$ & $599 / 1591$ & 0.79 & $0.56,1.11$ & $1329 / 1591$ & 0.80 & $0.63,1.02$ & $302 / 1591$ & 0.83 & $0.52,1.32$ \\
\hline$>383$ & $600 / 1593$ & 0.72 & $0.51,1.02$ & $1262 / 1593$ & 0.72 & $0.53,0.97$ & $262 / 1593$ & 0.66 & $0.35,1.25$ \\
\hline$P$ for trend & & \multicolumn{2}{|c|}{0.05} & \multicolumn{3}{|c|}{0.02} & & \multicolumn{2}{|c|}{0.17} \\
\hline
\end{tabular}

Ref., reference category.

Significant $P$ values are indicated in bold font.

*Survey logistic regression models were used after adjustment for age, sex, race, educational attainment, household income, smoking status, alcohol drinking, physical activity, BMI, daily intakes of total energy, $\mathrm{Mg}$ or $\mathrm{Ca}$, supplemental $\mathrm{Ca}$ intake (yes or no) and supplemental Mg intake (yes or no). 
Table 3 The association of intake of calcium with fatty liver disease, prediabetes and both fatty liver disease and prediabetes, stratified by sex, ratio of calcium intake to magnesium intake and drinking status: US adults aged $\geq 20$ years ( $n$ 13489), Third National Health and Nutrition Examination Survey (NHANES III), 1988-1994*

\begin{tabular}{|c|c|c|c|c|c|c|c|c|c|}
\hline \multirow[b]{2}{*}{ Daily intake (mg) } & \multicolumn{3}{|c|}{ Fatty liver disease $v$. Controls } & \multicolumn{3}{|c|}{ Prediabetes v. Controls } & \multicolumn{3}{|c|}{ Prediabetes \& fatty liver disease $v$. Controls } \\
\hline & Cases/controls & OR & $95 \% \mathrm{Cl}$ & Cases/controls & OR & $95 \% \mathrm{Cl}$ & Cases/controls & OR & $95 \% \mathrm{Cl}$ \\
\hline $\mathrm{Ca}$ & \multicolumn{9}{|c|}{ Men } \\
\hline$\leq 431$ & $284 / 459$ & 1.00 & Ref. & $831 / 459$ & 1.00 & Ref. & $160 / 459$ & 1.00 & Ref. \\
\hline $431-690$ & $301 / 599$ & 0.75 & $0.49,1.15$ & $741 / 599$ & 0.82 & $0 \cdot 60,1 \cdot 11$ & $164 / 599$ & 0.59 & $0.35,1.01$ \\
\hline $690-1063$ & $337 / 691$ & 0.97 & $0.66,1.44$ & $745 / 691$ & 1.01 & $0.72,1.41$ & $173 / 691$ & 0.68 & $0.43,1.08$ \\
\hline$>1063$ & $348 / 876$ & 0.93 & $0.59,1.48$ & $792 / 876$ & $1 \cdot 12$ & $0.80,1.56$ & $149 / 876$ & 0.65 & $0.31,1.35$ \\
\hline$P$ for trend & \multicolumn{3}{|c|}{0.77} & \multicolumn{3}{|c|}{0.19} & & \multicolumn{2}{|c|}{0.46} \\
\hline \multicolumn{4}{|l|}{$\mathrm{Ca}$} & \multicolumn{3}{|c|}{ Women } & & & \\
\hline$\leq 431$ & $365 / 1141$ & 1.00 & Ref. & $1088 / 1141$ & 1.00 & Ref. & $175 / 1141$ & 1.00 & Ref. \\
\hline$\overline{431-690}$ & $320 / 1005$ & $1 \cdot 17$ & $0.77,1.78$ & $705 / 1005$ & 1.06 & $0.81,1.39$ & $148 / 1005$ & $1 \cdot 10$ & $0.73,1.65$ \\
\hline $690-1063$ & $279 / 905$ & $1 \cdot 35$ & $0.87,2.09$ & $540 / 905$ & 1.04 & $0.78,1.40$ & $101 / 905$ & 0.99 & $0.65,1.49$ \\
\hline$>1063$ & $189 / 723$ & 1.45 & $0.93,2.26$ & $376 / 723$ & 1.02 & $0.76,1.36$ & $81 / 723$ & $1 \cdot 36$ & $0.73,2.56$ \\
\hline$P$ for trend & \multicolumn{3}{|c|}{0.06} & \multicolumn{3}{|c|}{0.91} & & \multicolumn{2}{|c|}{0.48} \\
\hline$P$ for interaction & \multicolumn{3}{|c|}{0.79} & \multicolumn{3}{|c|}{0.25} & \multirow{2}{*}{\multicolumn{3}{|c|}{0.52}} \\
\hline $\mathrm{Ca}$ & & & & & Ca:M & $<2.6$ & & & \\
\hline$\leq 431$ & $575 / 1361$ & 1.00 & Ref. & $1656 / 1361$ & 1.00 & Ref. & $297 / 1361$ & 1.00 & Ref. \\
\hline$\overline{431-690}$ & $392 / 1036$ & 0.81 & $0.59,1.09$ & $912 / 1036$ & 0.80 & $0.60,1.06$ & $203 / 1036$ & 0.60 & $0.38,0.94$ \\
\hline $690-1063$ & $291 / 662$ & 1.05 & $0.74,1.49$ & $592 / 662$ & 1.00 & $0.73,1.38$ & $144 / 662$ & 0.65 & $0.41,1.04$ \\
\hline$>1063$ & $98 / 264$ & 1.59 & $0.87,2.90$ & $211 / 264$ & 1.41 & $0.82,2.42$ & $38 / 264$ & 0.80 & $0.34,1.83$ \\
\hline$P$ for trend & \multicolumn{3}{|c|}{0.17} & \multicolumn{3}{|c|}{0.27} & & \multicolumn{2}{|c|}{0.27} \\
\hline \multicolumn{4}{|l|}{$\mathrm{Ca}$} & \multicolumn{3}{|c|}{ Ca:Mg $\geq 2.6$} & & & \\
\hline$\leq 431$ & $74 / 239$ & 1.00 & Ref. & $263 / 239$ & 1.00 & Ref. & $38 / 239$ & 1.00 & Ref. \\
\hline$\overline{431-690}$ & $229 / 568$ & $1 \cdot 88$ & $0.83,4.25$ & $534 / 568$ & 1.75 & $1.08,2.83$ & $109 / 568$ & 1.75 & $0.78,3.94$ \\
\hline $690-1063$ & $325 / 934$ & 1.98 & $0.73,5.36$ & $693 / 934$ & $1 \cdot 70$ & $0.90,3.22$ & $130 / 934$ & $1 \cdot 78$ & $0.66,4.77$ \\
\hline$>1063$ & $439 / 1335$ & 1.90 & $0.62,5.76$ & $957 / 1335$ & 1.98 & $1.07,3.67$ & $192 / 1335$ & 2.53 & $0.72,8.97$ \\
\hline$P$ for trend & & & .57 & & & 12 & & & \\
\hline$P$ for interaction & & 0.20 & & & 0.14 & & & 0.89 & \\
\hline $\mathrm{Ca}$ & & & & Neve & er alco & lol drinkers & & & \\
\hline$\leq 431$ & $109 / 292$ & 1.00 & Ref. & $339 / 292$ & 1.00 & Ref. & $64 / 292$ & 1.00 & Ref. \\
\hline$\overline{431-690}$ & $98 / 244$ & $1 \cdot 32$ & $0.71,2.45$ & $248 / 244$ & 0.89 & $0.57,1.41$ & $49 / 244$ & $1 \cdot 28$ & $0.47,3.49$ \\
\hline $690-1063$ & $95 / 251$ & $1 \cdot 33$ & $0.57,3.13$ & $215 / 251$ & 0.74 & $0.48,1.14$ & $30 / 251$ & 0.77 & $0.25,2.35$ \\
\hline$>1063$ & $64 / 200$ & $1 \cdot 14$ & $0.46,2.85$ & $152 / 200$ & 0.88 & $0.49,1.59$ & $26 / 200$ & 1.35 & $0.36,5.14$ \\
\hline$P$ for trend & & & .73 & & & .46 & & & \\
\hline $\mathrm{Ca}$ & & & & Form & ler alc & hol drinkers & & & \\
\hline$\leq 431$ & $211 / 528$ & 1.00 & Ref. & $638 / 528$ & 1.00 & Ref. & $118 / 528$ & 1.00 & Ref. \\
\hline$\overline{431-690}$ & $232 / 511$ & 0.94 & $0.73,1.20$ & $566 / 511$ & 0.94 & $0.73,1.21$ & $133 / 511$ & 1.09 & $0.67,1.77$ \\
\hline $690-1063$ & $197 / 476$ & $1 \cdot 16$ & $0.89,1.51$ & $454 / 476$ & 1.09 & $0.85,1.40$ & $98 / 476$ & 0.94 & $0.57,1.57$ \\
\hline$>1063$ & $173 / 458$ & $1 \cdot 18$ & $0.84,1.66$ & $416 / 458$ & $1 \cdot 16$ & $0.90,1.50$ & $82 / 458$ & 0.89 & $0.41,1.93$ \\
\hline$P$ for trend & & & .16 & & & 12 & & & \\
\hline $\mathrm{Ca}$ & & & & Curre & ent alc & hol drinkers & & & \\
\hline$\leq 431$ & $308 / 741$ & 1.00 & Ref. & $308 / 741$ & 1.00 & Ref. & $147 / 741$ & 1.00 & Ref. \\
\hline$\overline{431-690}$ & 283/822 & 0.82 & $0.56,1.20$ & $589 / 822$ & 0.87 & $0.64,1.19$ & $127 / 822$ & 0.57 & $0.32,1.00$ \\
\hline $690-1063$ & $311 / 844$ & 1.07 & $0.77,1.49$ & $577 / 844$ & 1.08 & $0.78,1.49$ & $140 / 844$ & 0.78 & $0.50,1.21$ \\
\hline$>1063$ & $288 / 916$ & $1 \cdot 13$ & $0.72,1.76$ & $567 / 916$ & $1 \cdot 16$ & $0.84,1.62$ & $118 / 916$ & 0.85 & $0.45,1.59$ \\
\hline$P$ for trend & & & 26 & & & 17 & & & \\
\hline$P$ for interaction & & 0.79 & & & 0.37 & & & 0.24 & \\
\hline
\end{tabular}

Ref., reference category.

*Survey logistic regression models were used after adjustment for age, sex, race, educational attainment, household income, smoking status, alcohol drinking, physical activity, BMI, daily intakes of total energy and $\mathrm{Mg}$, supplemental $\mathrm{Ca}$ intake (yes or no) and supplemental Mg intake (yes or no).

previous study ${ }^{(34)}$. However, that cross-sectional study conducted in Canadians had a very small sample size, which may have limited the power to detect an association. We also found that the inverse association between the intake of $\mathrm{Mg}$ and fatty liver disease appeared primarily in alcohol drinkers. Although novel, this finding is consistent with the observation that heavy alcohol drinkers are at high risk of $\mathrm{Mg}$ deficiency ${ }^{(12)}$. Future large-scale studies are needed to confirm the findings. This is important because previous studies have found that alcohol causes a substantial reduction in $\mathrm{Mg}$ homeostasis in the liver ${ }^{(13)}$. It was reported by NHANES 1999-2000 that $79 \%$ of US adults do not meet the
RDA for $\mathrm{Mg}^{(26)}$. One study observed that serum concentrations of Mg were significantly reduced in patients with either alcoholic or non-alcoholic liver steatosis ${ }^{(31)}$.

In a cohort study, the investigators found that intake of $\mathrm{Mg}$ was associated with a reduced risk metabolic syndrome ${ }^{(35)}$. Mg intake was also inversely associated with individual components of metabolic syndrome, particularly fasting glucose level, waist circumference and HDL cholesterol. Thus, the inverse association between the intake of $\mathrm{Mg}$ and metabolic syndrome is likely mediated through waist circumference or waist-to-hip ratio. Similarly, in our study, after additionally adjusting for 
Table 4 The association of intake of magnesium with fatty liver disease, prediabetes and both fatty liver disease and prediabetes, stratified by gender, ratio of calcium intake to magnesium intake, intake of calcium and drinking status: US adults aged $\geq 20$ years ( $n$ 13489), Third National Health and Nutrition Examination Survey (NHANES III), 1988-1994*

\begin{tabular}{|c|c|c|c|c|c|c|c|c|c|}
\hline \multirow[b]{2}{*}{ Daily intake (mg) } & \multicolumn{3}{|c|}{ Fatty liver disease $v$. Controls } & \multicolumn{3}{|c|}{ Prediabetes $v$. Controls } & \multicolumn{3}{|c|}{ Prediabetes \& fatty liver disease $v$. Controls } \\
\hline & Cases/controls & OR & $95 \% \mathrm{Cl}$ & Cases/controls & OR & $95 \% \mathrm{Cl}$ & Cases/controls & OR & $95 \% \mathrm{Cl}$ \\
\hline $\mathrm{Mg}$ & \multicolumn{9}{|c|}{ Men } \\
\hline$\leq 192$ & $234 / 399$ & 1.00 & Ref. & $702 / 399$ & 1.00 & Ref. & $130 / 399$ & 1.00 & Ref. \\
\hline $192-274$ & $245 / 488$ & $1 \cdot 10$ & $0.67,1.81$ & $697 / 488$ & 1.04 & $0.66,1.64$ & $119 / 488$ & 0.91 & $0.49,1.68$ \\
\hline $274-383$ & $345 / 734$ & 0.91 & $0.54,1.53$ & $779 / 734$ & 0.76 & $0.53,1.10$ & $193 / 734$ & 0.82 & $0.42,1.61$ \\
\hline $\begin{array}{l}>383 \\
P \text { for trend }\end{array}$ & \multicolumn{3}{|c|}{0.19} & \multicolumn{2}{|c|}{0.04} & $\begin{array}{l}0.49,1 \cdot 19 \\
0.04\end{array}$ & $204 / 1004$ & 0.60 & $\begin{array}{l}0.26,1.39 \\
0.19\end{array}$ \\
\hline $\mathrm{Mg}$ & & & & & & men & & & \\
\hline$\leq 192$ & $418 / 1216$ & 1.00 & Ref. & $1147 / 1216$ & 1.00 & Ref. & $202 / 1216$ & 1.00 & Ref. \\
\hline $192-274$ & $327 / 1112$ & 0.72 & $0.48,1.09$ & $681 / 1112$ & 0.75 & $0.56,1.02$ & $136 / 1112$ & 0.98 & $0.58,1.65$ \\
\hline $274-383$ & $254 / 857$ & 0.71 & $0.45,1.13$ & $550 / 857$ & 0.89 & $0.66,1.20$ & $109 / 857$ & 0.81 & $0.48,1.34$ \\
\hline $\begin{array}{l}>383 \\
P \text { for trend }\end{array}$ & \multicolumn{3}{|c|}{0.20} & \multicolumn{3}{|c|}{0.09} & $58 / 589$ & 0.67 & 0.25 \\
\hline$P$ for interaction & \multirow{2}{*}{\multicolumn{3}{|c|}{0.88}} & \multirow{2}{*}{\multicolumn{3}{|c|}{0.22}} & \multirow{2}{*}{\multicolumn{3}{|c|}{0.10}} \\
\hline $\mathrm{Mg}$ & & & & & & & & & \\
\hline$\leq 192$ & $336 / 771$ & 1.00 & Ref. & $1038 / 771$ & 1.00 & Ref. & $178 / 771$ & 1.00 & Ref. \\
\hline $192-274$ & $306 / 802$ & 0.77 & $0.53,1.13$ & $771 / 802$ & 0.85 & $0.61,1.20$ & $146 / 802$ & 0.81 & $0.48,1.37$ \\
\hline $274-383$ & $344 / 831$ & 0.78 & $0.52,1.18$ & $768 / 831$ & 0.81 & $0.58,1.13$ & $182 / 831$ & 0.77 & $0.42,1.40$ \\
\hline$>383$ & $370 / 919$ & 0.77 & $0.46,1.29$ & $794 / 919$ & 0.79 & $0.50,1.27$ & $176 / 919$ & 0.58 & $0.27,1.24$ \\
\hline$P$ for trend & \multicolumn{3}{|c|}{0.50} & \multicolumn{3}{|c|}{0.34} & & \multicolumn{2}{|c|}{0.16} \\
\hline $\mathrm{Mg}$ & & & & & Ca:N & $g \geq 2 \cdot 6$ & & & \\
\hline$\leq 192$ & $316 / 844$ & 1.00 & Ref. & $811 / 844$ & 1.00 & Ref. & $154 / 844$ & 1.00 & Ref. \\
\hline $192-274$ & $266 / 798$ & 0.91 & $0.56,1.47$ & $607 / 798$ & 0.83 & $0.59,1.19$ & $109 / 798$ & 0.99 & $0.60,1.63$ \\
\hline $274-383$ & $255 / 760$ & 0.81 & $0.41,1.58$ & $561 / 760$ & 0.77 & $0.51,1.15$ & $120 / 760$ & 0.87 & $0.43,1.78$ \\
\hline $\begin{array}{l}>383 \\
P \text { for trend }\end{array}$ & \multicolumn{3}{|c|}{0.23} & $468 / 674$ & 0.60 & $\begin{array}{l}0.38,0.96 \\
0.04\end{array}$ & $86 / 674$ & 0.66 & $\begin{array}{l}0 \cdot 20,2 \cdot 20 \\
0.46\end{array}$ \\
\hline$P$ for interaction & & 0.25 & & & 0.14 & & & 0.29 & \\
\hline $\mathrm{Mg}$ & & & & $\mathrm{Ca}$ & intake & $<1200 \mathrm{mg} / \mathrm{d}$ & & & \\
\hline$\leq 192$ & $648 / 1602$ & 1.00 & Ref. & $1841 / 1602$ & 1.00 & Ref. & $330 / 1602$ & 1.00 & Ref. \\
\hline $192-274$ & $543 / 1498$ & 0.75 & $0.53,1.08$ & $1305 / 1498$ & 0.83 & $0.63,1.09$ & $242 / 1498$ & 0.82 & $0.53,1.27$ \\
\hline $274-383$ & $485 / 1272$ & 0.70 & $0.50,0.99$ & $1091 / 1272$ & 0.82 & $0.63,1.07$ & $245 / 1272$ & 0.79 & $0.49,1.28$ \\
\hline $\begin{array}{l}>383 \\
P \text { for trend }\end{array}$ & $341 / 801$ & 0.66 & $\begin{array}{l}0.44,0.99 \\
0.04\end{array}$ & $707 / 801$ & 0.72 & $\begin{array}{l}0.49,1.06 \\
0.09\end{array}$ & $164 / 801$ & 0.66 & $\begin{array}{l}0.33,1.30 \\
0.25\end{array}$ \\
\hline $\mathrm{Mg}$ & & & & $\mathrm{Ca}$ & intake & $\geq 1200 \mathrm{mg} / \mathrm{d}$ & & & \\
\hline$\leq 192$ & $4 / 13$ & 1.00 & Ref. & $8 / 13$ & 1.00 & Ref. & $2 / 13$ & 1.00 & Ref. \\
\hline $192-274$ & $29 / 102$ & $1 \cdot 13$ & $0.23,5.53$ & 73/102 & $2 \cdot 51$ & $0.28,22 \cdot 36$ & $13 / 102$ & $5 \cdot 35$ & $0.51,56 \cdot 12$ \\
\hline $274-383$ & $114 / 319$ & 0.84 & $0.19,3.72$ & $238 / 319$ & 1.63 & $0.20,13.01$ & $57 / 319$ & 2.48 & $0.24,25.62$ \\
\hline $\begin{array}{l}>383 \\
P \text { for trend }\end{array}$ & $259 / 792$ & 0.87 & $\begin{array}{l}0.19,4.07 \\
0.74\end{array}$ & $555 / 792$ & 1.58 & $\begin{array}{l}0.20,12.69 \\
0.40\end{array}$ & $98 / 792$ & $2 \cdot 21$ & $\begin{array}{l}0.20,24.29 \\
0.41\end{array}$ \\
\hline$P$ for interaction & & 0.69 & & & 0.04 & & & 0.34 & \\
\hline $\mathrm{Mg}$ & & & & $\mathrm{Ne}$ & jer alc & hol drinkers & & & \\
\hline$\leq 192$ & $135 / 331$ & 1.00 & Ref. & $373 / 331$ & 1.00 & Ref. & $73 / 331$ & 1.00 & Ref. \\
\hline $192-274$ & $99 / 288$ & $1 \cdot 11$ & $0.58,2.14$ & $253 / 288$ & 0.87 & $0.55,1.37$ & $45 / 288$ & 1.02 & $0.37,2.80$ \\
\hline $274-383$ & $80 / 227$ & 0.93 & $0.46,1.90$ & $194 / 227$ & 0.85 & $0.49,1.46$ & $34 / 227$ & 0.86 & $0.37,1.99$ \\
\hline $\begin{array}{l}>383 \\
P \text { for trend }\end{array}$ & $52 / 141$ & $1 \cdot 18$ & $\begin{array}{l}0.57,2.43 \\
0.85\end{array}$ & $134 / 141$ & 0.66 & $\begin{array}{l}0.43,1.03 \\
0.08\end{array}$ & $17 / 141$ & 0.64 & $0_{0.46}^{0.17,2.49}$ \\
\hline $\mathrm{Mg}$ & & & & For & ner alc & ohol drinkers & & & \\
\hline$\leq 192$ & $239 / 570$ & 1.00 & Ref. & $671 / 570$ & 1.00 & Ref. & $141 / 570$ & 1.00 & Ref. \\
\hline $192-274$ & $190 / 504$ & 0.78 & $0.54,1.13$ & $520 / 504$ & 0.85 & $0.63,1.14$ & $93 / 504$ & 0.97 & $0.47,2.02$ \\
\hline $274-383$ & $212 / 457$ & 0.76 & $0.52,1.11$ & $480 / 457$ & 0.79 & $0.62,1.02$ & $116 / 457$ & 1.03 & $0.55,1.95$ \\
\hline $\begin{array}{l}>383 \\
P \text { for trend }\end{array}$ & $172 / 442$ & 0.67 & $\begin{array}{l}0.46,0.98 \\
0.04\end{array}$ & $403 / 442$ & 0.72 & $\begin{array}{l}0.52,1.01 \\
0.03\end{array}$ & $81 / 442$ & 0.66 & $\begin{array}{l}0.25,1.77 \\
0.45\end{array}$ \\
\hline $\mathrm{Mg}$ & & & & Cur & ent alc & ohol drinkers & & & \\
\hline$\leq 192$ & $265 / 672$ & 1.00 & Ref. & $508 / 672$ & 1.00 & Ref. & $115 / 672$ & 1.00 & Ref. \\
\hline $192-274$ & $267 / 785$ & 0.66 & $0.40,1.09$ & $559 / 785$ & 0.82 & $0.53,1.25$ & $112 / 785$ & 0.76 & $0.52,1.11$ \\
\hline $274-383$ & $296 / 885$ & 0.62 & $0.37,1.05$ & $615 / 885$ & 0.72 & $0.48,1.07$ & $149 / 885$ & 0.66 & $0.38,1.14$ \\
\hline $\begin{array}{l}>383 \\
P \text { for trend }\end{array}$ & $362 / 981$ & 0.58 & $\begin{array}{l}0.36,0.94 \\
0.04\end{array}$ & $676 / 981$ & 0.70 & $\begin{array}{l}0.43,1.12 \\
0.09\end{array}$ & $156 / 981$ & 0.54 & $\begin{array}{l}0.29,1.00 \\
0.13\end{array}$ \\
\hline$P$ for interaction & & 0.64 & & & 0.47 & & & 0.33 & \\
\hline
\end{tabular}

Ref., reference category.

Significant $P$ values are indicated in bold font.

*Survey logistic regression models were used after adjustment for age, sex, race, educational attainment, household income, smoking status, alcohol drinking, physical activity, BMI, daily intakes of total energy and $\mathrm{Ca}$, supplemental $\mathrm{Ca}$ intake (yes or no) and supplemental Mg intake (yes or no). 
waist-to-hip ratio, the significant associations disappeared. As such, waist-to-hip ratio may serve as a pathway to the relationship between $\mathrm{Mg}$ intake and the disease outcomes (i.e. fatty liver disease and/or prediabetes) or it could be an over-adjustment.

In the stratified analyses, we found intake of $\mathrm{Mg}$ may be more significantly related to reduced odds of prediabetes and fatty liver disease when Ca intake was $<1200 \mathrm{mg} / \mathrm{d}$. This finding suggests that the beneficial effect of $\mathrm{Mg}$ may be suppressed when Ca intake is higher than the Dietary Reference Intake. This finding is consistent with our recent finding indicating that $\mathrm{Ca}$ intake may interact with $\mathrm{Mg}$ intake in relation to risks of multiple common diseases $^{(23-26)}$. Some ${ }^{(36-38)}$, but not all ${ }^{(39)}$, previous human studies indicate that high $\mathrm{Ca}$ intake may affect the absorption rate of $\mathrm{Mg}$. It is known that over $80 \%$ of plasma $\mathrm{Mg}$ is ultrafiltrated and reabsorbed in the kidneys. Thus, kidney reabsorption plays a key role in regulating $\mathrm{Mg}$ homeostasis $^{(40)}$. Likewise, $10 \mathrm{~g}$ of $\mathrm{Ca}$ is filtered daily on average, of which $98 \%$ is reabsorbed in the kidneys ${ }^{(41,42)}$. Thus far, clinical trials have consistently found that high $\mathrm{Ca}$ intake leads to significantly increased excretion of $\mathrm{Mg}$ in the urine ${ }^{(40,43,44)}$. Thus, it is likely that high intake of $\mathrm{Ca}$ may lead to relative deficiency of $\mathrm{Mg}$. We also found $\mathrm{Mg}$ intake may only be associated with reduced odds of fatty liver disease among former and current drinkers. This finding is possible because alcohol drinkers are at high risk of $\mathrm{Mg}$ deficiency ${ }^{(12)}$. However, further large studies, particularly longitudinal studies, are necessary to replicate the findings.

A strength of our study is that it is used data from NHANES, a population-based study with a nationally representative sample. However, although multiple $24 \mathrm{~h}$ dietary recalls are used as a gold standard measure in nutritional epidemiological studies, a one-time $24 \mathrm{~h}$ dietary recall as used in the current study may not have adequately captured long-term dietary intakes of $\mathrm{Mg}$ and $\mathrm{Ca}$. Since inter-day variation in intakes of $\mathrm{Mg}$ and $\mathrm{Ca}$ is random, any residual inter-day variation in the current study would lead to non-differential misclassification, which usually biases the result to the null. Thus, the true association between intakes of $\mathrm{Mg}$ and $\mathrm{Ca}$ and risk of prediabetes and fatty liver disease may be stronger than what we have observed. We cannot eliminate the possibility that the associations with intakes of $\mathrm{Mg}$ and $\mathrm{Ca}$ are due to residual confounding factors or healthy lifestyle in general. However, we have adjusted for physical activity and BMI as well as total energy intake. Furthermore, in the same analysis, we found the associations of $\mathrm{Ca}$ and $\mathrm{Mg}$ are in opposite directions. Thus, it is unlikely our findings are due to confounding by healthy lifestyle in general because those who possess healthy behaviours are likely to use Ca supplements. Finally, like all cross-sectional studies, the temporal sequence for the associations is not clear. However, the inverse association between intake of $\mathrm{Mg}$ and risk of prediabetes is consistent with the associations of Mg with insulin resistance ${ }^{(16)}$, metabolic syndrome ${ }^{(17,31)}$ and type 2 diabetes ${ }^{(18,19)}$.

\section{Conclusion}

In conclusion, our findings suggest that high intake of $\mathrm{Mg}$ may be associated with lower odds of having fatty liver disease and prediabetes, whereas high intake of Ca was overall not related to the risk. The associations may appear primarily in those whose Ca intake is less than $1200 \mathrm{mg} / \mathrm{d}$. Further studies, particularly prospective cohort studies, are warranted to confirm or refute these findings.

\section{Acknowledgements}

Financial support: X.Z. and Q.D. were supported by the National Cancer Institute, Department of Health and Human Services (Q.D., grant number R01 CA202936). The National Cancer Institute had no role in the design, analysis or writing of this article. Conflict of interest: All authors have no conflicts of interest. Authorship: Conceptualization, J.L. and Q.D.; methodology and formal analysis, X.Z.; writing - original draft, W.L. and Q.D.; writing - review and editing, X.Z., Y.S., L.F., L.W., E.K.K., L.H., M.J.S., J.L. and Q.D.; funding acquisition, Q.D. and X.Z. Etbics of human subject participation: This study was conducted according to the guidelines laid down in the Declaration of Helsinki and all procedures involving human subjects were approved by the institutional review board of the Centers for Disease Control and Prevention. Written informed consent was obtained from all subjects.

\section{References}

1. Peery AF, Crockett SD, Barritt AS et al. (2015) Burden of gastrointestinal, liver, and pancreatic diseases in the United States. Gastroenterology 149, 1731-1741.e3.

2. GBD 2015 Mortality and Causes of Death Collaborators (2016) Global, regional, and national life expectancy, allcause mortality, and cause-specific mortality for 249 causes of death, 1980-2015: a systematic analysis for the Global Burden of Disease Study 2015. Lancet 388, 1459-1544.

3. Blachier M, Leleu H, Peck-Radosavljevic M et al. (2013) The burden of liver disease in Europe: a review of available epidemiological data. J Hepatol 58, 593-608.

4. Bedogni G, Miglioli L, Masutti F et al. (2005) Prevalence of and risk factors for nonalcoholic fatty liver disease: the Dionysos nutrition and liver study. Hepatology 42, 44-52.

5. Wong RJ, Aguilar M, Cheung R et al. (2015) Nonalcoholic steatohepatitis is the second leading etiology of liver disease among adults awaiting liver transplantation in the United States. Gastroenterology 148, 547-555.

6. Lazo M, Hernaez R, Eberhardt MS et al. (2013) Prevalence of nonalcoholic fatty liver disease in the United States: the Third National Health and Nutrition Examination Survey, 1988-1994. Am J Epidemiol 178, 38-45.

7. Matteoni CA, Younossi ZM, Gramlich T et al. (1999) Nonalcoholic fatty liver disease: a spectrum of clinical and pathological severity. Gastroenterology 116, 1413-1419. 
8. Godos J, Federico A, Dallio M et al. (2017) Mediterranean diet and nonalcoholic fatty liver disease: molecular mechanisms of protection. Int J Food Sci Nutr 68, 18-27.

9. Chang Y, Jung H-S, Cho J et al. (2016) Metabolically healthy obesity and the development of nonalcoholic fatty liver disease. Am J Gastroenterol 111, 1133-1140.

10. Fierbinteanu-Braticevici C, Sinescu C, Moldoveanu A et al. (2017) Nonalcoholic fatty liver disease: one entity, multiple impacts on liver health. Cell Biol Toxicol 33, 5-14.

11. Marchesini G, Brizi M, Bianchi G et al. (2001) Nonalcoholic fatty liver disease: a feature of the metabolic syndrome. Diabetes 50, 1844-1850.

12. Rivlin RS (1994) Magnesium deficiency and alcohol intake: mechanisms, clinical significance and possible relation to cancer development (a review). J Am Coll Nutr 13, 416-423.

13. Young A, Cefaratti C \& Romani A (2003) Chronic EtOH administration alters liver $\mathrm{Mg}^{2+}$ homeostasis. Am J Physiol Gastrointest Liver Physiol 284, G57-G67.

14. Gommers LMM, Hoenderop JGJ, Bindels RJM et al. (2016) Hypomagnesemia in type 2 diabetes: a vicious circle? Diabetes 65, 3-13.

15. Turecky L, Kupcova V, Szantova M et al. (2006) Serum magnesium levels in patients with alcoholic and nonalcoholic fatty liver. Bratisl Lek Listy 107, 58-61.

16. Song Y, He K, Levitan EB et al. (2006) Effects of oral magnesium supplementation on glycaemic control in type 2 diabetes: a meta-analysis of randomized double-blind controlled trials. Diabet Med 23, 1050-1056.

17. Champagne CM (2008) Magnesium in hypertension, cardiovascular disease, metabolic syndrome, and other conditions: a review. Nutr Clin Pract 23, 142-151.

18. Song Y, Manson JE, Buring JE et al. (2004) Dietary magnesium intake in relation to plasma insulin levels and risk of type 2 diabetes in women. Diabetes Care 27, 59-65.

19. Dong J-Y, Xun P, He K et al. (2011) Magnesium intake and risk of type 2 diabetes: meta-analysis of prospective cohort studies. Diabetes Care 34, 2116-2122.

20. Wu L, Zhu X, Fan L et al. (2017) Magnesium intake and mortality due to liver diseases: results from the Third National Health and Nutrition Examination Survey Cohort. Sci Rep 7, 17913.

21. Pittas AG, Lau J, Hu FB et al. (2007) The role of vitamin D and calcium in type 2 diabetes. A systematic review and meta-analysis. J Clin Endocrinol Metab 92, 2017-2029.

22. Drouillet P, Balkau B, Charles MA et al. (2007) Calcium consumption and insulin resistance syndrome parameters. Data from the Epidemiological Study on the Insulin Resistance Syndrome (DESIR). Nutr Metab Cardiovasc Dis 17, 486-492.

23. Dai Q, Shrubsole MJ, Ness RM et al. (2007) The relation of magnesium and calcium intakes and a genetic polymorphism in the magnesium transporter to colorectal neoplasia risk. Am J Clin Nutr 86, 743-751.

24. Dai Q, Sandler RS, Barry EL et al. (2012) Calcium, magnesium, and colorectal cancer. Epidemiology 23, 504-505.

25. Dai Q, Cantwell MM, Murray LJ et al. (2016) Dietary magnesium, calcium:magnesium ratio and risk of reflux oesophagitis, Barrett's oesophagus and oesophageal adenocarcinoma: a population-based case-control study. Br J Nutr 115, 342-350.

26. Dai Q, Shu X-O, Deng X et al. (2013) Modifying effect of calcium/magnesium intake ratio and mortality: a population-based cohort study. BMJ Open 3, e002111.

27. Centers for Disease Control and Prevention (2011) NHANES 1988-1994: Hepatic/Gallbladder Ultrasound and Hepatic Steatosis Data Documentation, Codebook, and Frequencies.
http://www.cdc.gov/nchs/nhanes/nhanes3/HGUHS.htm (accessed December 2016).

28. American Diabetes Association (2011) Diagnosis and classification of diabetes mellitus. Diabetes Care 34, Suppl. 1, S62-S69.

29. Sjögren A, Florén CH \& Nilsson A (1988) Oral administration of magnesium hydroxide to subjects with insulin-dependent diabetes mellitus: effects on magnesium and potassium levels and on insulin requirements. Magnesium 7, 117-122.

30. Paolisso G, Sgambato S, Pizza G et al. (1989) Improved insulin response and action by chronic magnesium administration in aged NIDDM subjects. Diabetes Care 12, 265-269.

31. He K, Song Y, Belin RJ et al. (2006) Magnesium intake and the metabolic syndrome: epidemiologic evidence to date. J Cardiometab Syndr 1, 351-355.

32. Pagano G, Pacini G, Musso G et al. (2002) Nonalcoholic steatohepatitis, insulin resistance, and metabolic syndrome: further evidence for an etiologic association. Hepatology 35, 367-372.

33. Hruby A, Meigs JB, O'Donnell CJ et al. (2014) Higher magnesium intake reduces risk of impaired glucose and insulin metabolism and progression from prediabetes to diabetes in middle-aged Americans. Diabetes Care 37, 419-427.

34. Da Silva HE, Arendt BM, Noureldin SA et al. (2014) A crosssectional study assessing dietary intake and physical activity in Canadian patients with nonalcoholic fatty liver disease vs healthy controls. J Acad Nutr Diet 114, 1181-1194.

35. He K, Liu K, Daviglus ML et al. (2006) Magnesium intake and incidence of metabolic syndrome among young adults. Circulation 113, 1675-1682.

36. Hardwick LL, Jones MR, Brautbar N et al. (1991) Magnesium absorption: mechanisms and the influence of vitamin $\mathrm{D}$, calcium and phosphate. J Nutr 121, 13-23.

37. Norman DA, Fordtran JS, Brinkley LJ et al. (1981) Jejunal and ileal adaptation to alterations in dietary calcium: changes in calcium and magnesium absorption and pathogenetic role of parathyroid hormone and 1,25-dihydroxyvitamin D. J Clin Invest 67, 1599-1603.

38. Abrams SA, Grusak MA, Stuff J et al. (1997) Calcium and magnesium balance in 9-14-y-old children. Am J Clin Nutr 66, 1172-1177.

39. Institute of Medicine, Standing Committee on the Scientific Evaluation of Dietary Reference Intakes (1997) Dietary Reference Intakes for Calcium, Phosphorus, Magnesium, Vitamin D, and Fluoride. Washington, DC: National Academies Press.

40. Hoenderop JGJ \& Bindels RJM (2005) Epithelial $\mathrm{Ca}^{2+}$ and $\mathrm{Mg}^{2+}$ channels in health and disease. J Am Soc Nephrol 16, $15-26$.

41. Monnens L, Starremans P \& Bindels R (2000) Great strides in the understanding of renal magnesium and calcium reabsorption. Nephrol Dial Transplant 15, 568-571.

42. Guéguen L \& Pointillart A (2000) The bioavailability of dietary calcium. J Am Coll Nutr 19, 2 Suppl., 119S-136S.

43. Green JH, Booth C \& Bunning R (2003) Acute effect of highcalcium milk with or without additional magnesium, or calcium phosphate on parathyroid hormone and biochemical markers of bone resorption. Eur J Clin Nutr 57, 61-68.

44. Nielsen FH, Milne DB, Gallagher S et al. (2007) Moderate magnesium deprivation results in calcium retention and altered potassium and phosphorus excretion by postmenopausal women. Magnes Res 20, 19-31. 